\title{
Synthesis of Aromatic Polyamide Dendrimers by an Orthogonal Approach
}

\author{
Yuichi Ishida, Mitsutoshi Jikei, and Masa-aki Kakimoto \\ Department of Organic and Polymeric Materials, Tokyo Institute of Technology, \\ Meguro-ku, Tokyo 152-8552, Japan
}

Key words: dendrimer, aromatic polyamide, orthogonal approach

\section{Introduction}

Dendritic macromolecules such as dendrimers and hyperbranched polymers have received considerable attention in recent years.[1-5] These polymers have unique properties such as small radius of gyration, lack of entanglement, low viscosity, high solubility, amorphous nature, and so on. Particularly, dendrimers, which have a well-controlled structure and size, have utilized many uses, including harvesting of low-energy photons[6], drug-delivery agents[7], unimolecular micelles[8]. Generally, dendrimers were synthesized by the divergent [9-10] and the convergent[11] strategies. These synthetic routes require a deprotection step in addition to the coupling step and purification for each new generation. Several years ago, Zeng and Zimmerman have reported a synthesis of dendrimers by an orthogonal approach, in which deprotection steps are not required by sequential use of two different building blocks in two coupling reactions.[12] Although this approach halves the number of steps, the resulting dendrimers consisted of alternating copolymer because of utilization of two different coupling reactions. However, if two monomer units were designed to couple by two different reactions to form a same linkage, homogeneous dendrimers could be obtained. Yu et al. have reported a synthesis of poly(phenylenevinylene) dendrimers by this approach.[13] We now describe a synthesis of aromatic polyamide dendrimers[14] by an orthogonal approach, in which an alternate utilization of the direct condensation reaction and palladium-catalyzed $\mathrm{CO}$ insertion reaction to form an amide linkage.

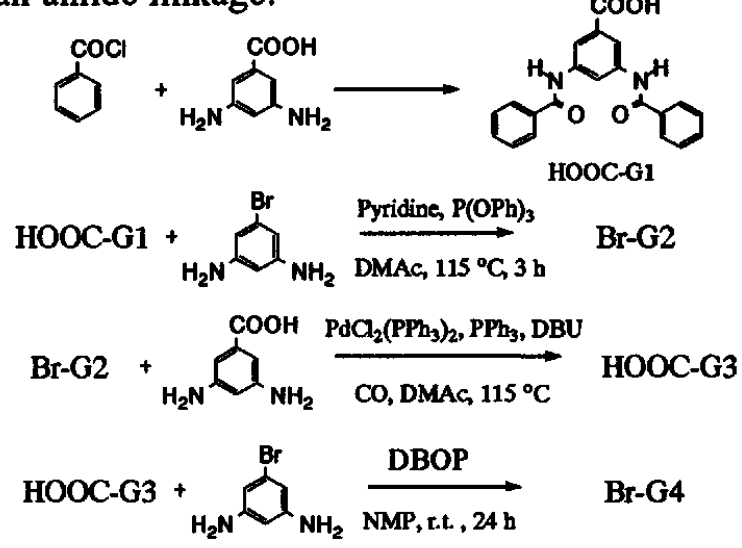

Fig. 1 Synthetic route of aromatic polyamide dendrons by an orthogonal approach.

\section{Results and Discussion}

3,5-diaminobenzoic acid and 3,5diaminobromobenzene were selected as building blocks. At first, 3,5-diaminobenzoic acid was reacted with benzoyl chloride in DMAc to obtain the first generation dendron (HOOC-G1). The brownish powder was obtained in $93 \%$ yield by pouring reaction mixture into dilute $\mathrm{HCl}$ water. Further purification of HOOC-G1 was done by dissolving the product into THF and reprecipitating in hexane.

The second generation dendron $(\mathrm{Br}-\mathrm{G} 2)$ was prepared starting from HOOC-G1 and 3,5diaminobromobenzene in DMAc using the direct condensation reaction in the presence of triphenyl phosphite and pyridine as condensing agents. The crude product was precipitated by pouring into dilute $\mathrm{HCl}$ water. Then the precipitate was dissolved in THF / DMAc $(9: 1)$, followed by 

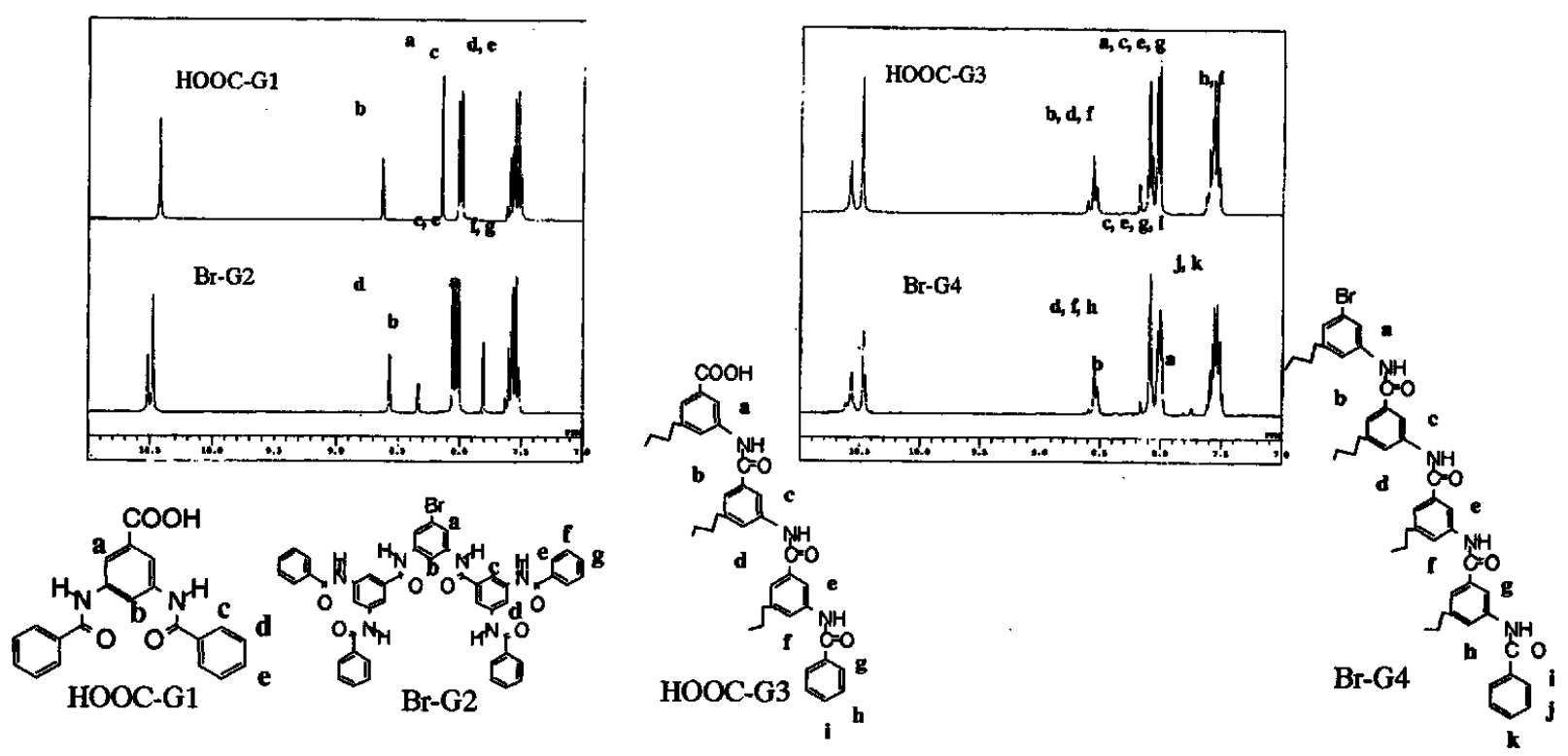

Fig. 2 ' $\mathrm{H}$-NMR spectra of aromatic polyamide dendrons.

pouring into methanol to reprecipitate $\mathrm{Br}-\mathrm{G} 2$. The yield was $83 \%$, and the product was pure, as judged by ${ }^{1} \mathrm{H}-\mathrm{NMR}$ spectroscopy.

The first and second generation dendrons were able to be isolated by the simple reprecipitation technique, thus these dendrons can be synthesized easily on a large scale.

The third generation dendron (HOOC-G3) was synthesized from $\mathrm{Br}-\mathrm{G} 2$ and 3,5-diaminobenzoic acid by the palladium-catalyzed $\mathrm{CO}$ insertion reaction. The reaction of $\mathrm{Br}-\mathrm{G} 2$ and $3,5-$ diaminobenzoic acid with carbon monoxide proceeded in the presence of $\mathrm{PdCl}_{2}\left(\mathrm{PPh}_{3}\right)_{2}, \mathrm{PPh}_{3}$, and 1,8-diazabicyclo[5.4.0]-7-undecene (DBU) as a base in DMAc at $115^{\circ} \mathrm{C}$. The grayish powder was obtained when the reaction solution was poured into dilute $\mathrm{HCl}$ water. The reprecipitated product was isolated by precipitation of THF / DMAc (9:1) - ethyl acetate system. However, GPC curve of the product showed two peaks, which correspond to HOOC-G3 and one-substituted building block. HOOC-G3 was finally isolated using the preparative GPC in $48 \%$ yield. The structure of HOOC-G3 was confirmed by ${ }^{1}$ H-NMR and MALDI-TOF MS spectroscopy.

The fourth generation dendron (Br-G4) was synthesized from HOOC-G3 and 3,5diaminobromobenzene by the direct condensation reaction using (2,3-dihydro-2thioxo-3-benzoxazolyl)phosphonic acid diphenyl ester (DBOP) as a condensing agent. The product was isolated by the same procedure as HOOC-G3 in $54 \%$ yield.

In conclusion, the fourth generation dendron constructed by only amide linkage, with molecular weights of $3731 \mathrm{~g} \mathrm{~mol}^{-1}$, was synthesized in just four steps. This means that the orthogonal approach will be applicable to a rapid synthesis of dendrimers with high molecular weights.

\section{References}

1. D. A. Tomalia, Adv. Mater., 6 (1994) 529.

2. J. M. J. Fréchet, Science, 263 (1994) 1771.

3. N. Ardoin and D. Astruc, Bull. Soc. Chim. Fr., 132 (1995) 875.

4. F. Zeng and S. C. Zimmerman, Chem. Rev, 97 (1997) 1681.

5. A. Matthews, A. N. Shipway and J. F. Stoddart, Prog. Polym. Sci., 23 (1998) 1.

6. D.-L. Jiang and T. Aida, Nature., 388 (1997) 1681.

7. K. Uhrich, TRIP, 5 (1997) 388.

8, C. J. Hawker, K. L. Wooley and J. M. J. Fréchet, J. Chem. Soc., Parkin Trans 1, (1993) 1287.

9. D. A. Tomalia, A. N. Naylor and W. A. Goddard, Angew. Chem., Int. Ed. Engl., 29 (1990) 138.

10. C. N. Moorefield, G. R. Newkome and G. R. Baker, Aldrichimica Acta, 25 (1992) 31.

11. K. L. Wooley, C. J. Hawker and J. M. J. Fréchet, J. Am. Chem. Soc., 113 (1991) 4252.

12. F. Zeng and S. C. Zimmerman, J. Am. Chem. Soc., 118 (1996) 5326.

13. S. K. Deb, T. M. Maddux and L. Yu, J. Am. Chem. Soc., 119 (1997) 9079.

14. S. C. E. Backson, P. M. Bayliff, W. J. Feast, A. M. Kenwright, D. Parker and R. W. Richards, Macromol. Symp., 77 (1994) 1. 